\section{Evaluation of the Lapillar Otolith Shape as a Tool for Discrimination of Stock of Naked Carp, Gymnocypris selincuoensis in the Tibetan Plateau}

\author{
Kang Chen ${ }^{1,2}$, Dekui He ${ }^{1}$, Chengzhi Ding ${ }^{3,4}$, Yintao Jia ${ }^{1}$ and Yifeng Chen ${ }^{1 *}$ \\ ${ }^{1}$ Laboratory of Biological Invasion and Adaptive Evolution, Institute of Hydrobiology, \\ Chinese Academy of Sciences, 430072, Wuhan, China \\ ${ }^{2}$ University of Chinese Academy of Sciences, Beijing 100049, China \\ ${ }^{3}$ Institute of International Rivers and Eco-security, Yunnan University, Kunming, Yunnan \\ 650091, China \\ ${ }^{4} Y u n n a n$ Key Laboratory of International Rivers and Transboundary Eco-Security, \\ Yunnan University, Kunming 650091, China
}

\begin{abstract}
A B S T R A C T
Otolith geographic variability is investigated as a tool for fish stock discrimination. Despite increasing studies of otoliths in marine ecosystems, feasibility of otolith shape as an investigative tool in freshwater fish assemblages needs to be validated. The aim of this study was to test stocks of Gymnocypris selincuoensis that may be distinguished using otolith shape from three rivers and eight lakes in northern Tibet. Shape indices (SDs) (form-factor, circularity, rectangularity, ellipticity, roundness, surface density and aspect ratio) and normalized Elliptic Fourier descriptors (NEFDs) were analysed by multivariate statistical procedures. To examine the differences of otolith shape from different sites, metric multidimensional scaling and a linear discriminant analysis were used for the SDs and NEFDs. The results of the linear discriminant analysis indicate that riverine otolith stocks had higher rates of successful classification compared with lacustrine otolith stocks, and stocks of otoliths from the Chargut Co and the Kyaring Co lakes had the highest rates of misclassification. Although a $70 \%$ classification success rate was produced by Bochu Tsangpo, the differences in otolith shape among 11 stocks were not very noteworthy. The information generated in this research can be used as a reference for stock discrimination of $G$. selincuoensis from the Tibetan Plateau. Further research is needed to explore the causes of shape variation.
\end{abstract}

\begin{tabular}{l} 
Article Information \\
Received 02 September 2019 \\
Revised 22 November 2019 \\
Accepted 12 December 2019 \\
Available online 11 October 2021 \\
Authors' Contribution \\
\hline KC carried out the experiments and \\
drafted the manuscript. YC and \\
DH participated in the design and \\
coordination of the study. DH, YJ and \\
CD participated in sample collection \\
and data analysis. \\
Key words \\
Northern tibet, Gymnocypris \\
selincuoensis, Otolith shape, Stock \\
discrimination, Elliptical Fourier \\
analysis
\end{tabular}
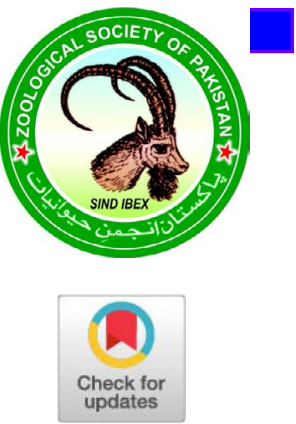
Otolith shape indices (SDs) and normalized elliptical Fourier descriptors (NEFDs) of contours are two fundamental shape variables that are used frequently for fish stock discriminations. Comparing the two SDs are used to directly describe otolith frame structures in the form of manual distance measurements, whereas Elliptical Fourier analysis is deemed as useful tool for capturing outline information efficiently in a quantifiable manner (Avigliano et al., 2018; Kuhl and Giardina, 1982; Torres et al., 2000). Elliptical Fourier analyses have been widely used in identifying marine fish assemblages (Bird et al., 1986; Campana and Casselman, 1993), because of the advantages in accommodating significantly more complex shapes when compared with polar Fourier functions. However, SDs and NEFDs are generally combined for stock discrimination for improvement of classification success (Agüera and Brophy, 2011; Dou et al., 2012; Moreira et al., 2019; Tracey et al., 2006).

Despite the increasing studies of identifying fish stocks with otolith morphology throughout the world, feasibility of otolith shape in discriminating freshwater fish stocks needs more exploration (Bostanci et al., 2015). Different marine fish species have large pairs of sagittal otoliths and have frequently been used as materials for species identification (Campana and Casselman, 1993).In freshwater Cypriniformes, especially for Schizothoracine fishes, sagittal otolith cannot be used for morphological analysis because its special aciculiform shape makes its extracting and measurement difficult. Lapillar otoliths of Schizothoracine fishes have moderate size and stable shapes, which are generally used for studying life history (Chen et al., 2009; Jia and Chen, 2009; Li et al., 2009). However, there has been surprisingly little effort to use lapillar otoliths as study objects to identify discrete stocks on an intra-species scale (Assis, 2007; Bostanci et al., 2015; Campana and Casselman, 1993). The understanding of lapillar otolith shapes for stock discrimination is imperative for validation in freshwater ecosystems.

Schizothoracine fishes are group of Cyprinidae living in high elevation rivers and lakes in the QinghaiTibetan Plateau (Cao et al., 1981; Chen et al., 2001b). Schizothoracine species are characterized by restricted distributions, low growth rate, and late sexual maturity as a result of adapting to rigorous environment (Chen and Cao, 2000; Wu and Wu, 1992). Naked carp species (Genus Gymnocypris) are one of the specialized groups within Schizothoracines that belong to the subfamily Schizothoracinae of Cyprinidae (Chen and Cao, 2000) and are mainly distributed in the middle and upper reaches of rivers and lakes on the Tibetan Plateau with an elevation range of 1500 to $5000 \mathrm{~m}$ (Ding et al., 2015; He and Chen, 2007). Numerous rivers and lakes constitute an enclosed basin system in northern Tibet, and naked carp species that were distributed in this system consist of multiple stocks (Chen et al., 2001b; Liang et al., 2017). Recent empirical studies made efforts to identify the fish stock by physical features; but, no evidence of separate stocks was found using external morphological characteristics or organ form features which could be used for fish stock classification (Liang, 2017; Wu and $\mathrm{Wu}$, 1992). Molecular experiments of cytochrome $b$ also demonstrated a low genetic differentiation among Schizothoracines (He et al., 2016; He and Chen, 2007). Therefore, these rivers and lakes are ideal sites for investigating the potential of using lapillar otolith shapes for identification of freshwater fish stocks.

Although otolith morphometrics have never been used in Schizothoracine fish, the moderate size and stable structure of lapillar otoliths allow them to potentially create two dimensional images that can be compared statistically (Jia and Chen, 2009). The aims of this study were to 1) evaluate the presence of lapillar otolith shape differences in different fish stocks of G. selincuoensis fishes, and 2) examine the utility of the lapillar otolith shape for stock discrimination in G. selincuoensis fishes.

\section{MATERIALS AND METHODS}

\section{Study area and sample collection}

The Qinghai-Tibetan Plateau possesses the highest lakes and rivers in the world; the total lake area exceeds $41,000 \mathrm{~km}^{2}$ and accounts for approximately one half of the total Chinese lake area (Ma et al., 2011). Siling Co lake $\left(88^{\circ} 33^{\prime}-89^{\circ} 21^{\prime}{ }^{\circ} \mathrm{E}, 31^{\circ} 34^{\prime}-31^{\circ} 51^{\prime}{ }^{\circ} \mathrm{N}\right)$ is located in northern Tibet (4300-7100 $\mathrm{m}$ above sea level) and is the largest lake in Tibet with an area of $2360 \mathrm{~km}^{2}$ (Che et al., 2015). Lakes (Siling Co, Nagtsang Co, Chikul Co) and rivers (Tsachu Tsangpo, Chargut Tsangpo, Bochu Tsangpo) in northern Tibet are connected and constitute an enclosed basin system with various hydrological characteristics, such as temperature, depth and salinity (Bian et al., 2010; Chen et al., 2001a) (Fig. 1).

G. selincuoensis were collected from three rivers: the Bochu Tsangpo (BT), the Chargut Tsangpo (CT), and the Tsachu Tsangpo (TT), and eight lakes: the Siling Co (SC), the Nagtsang Co (NC), the Kyaring Co (KC), the Mokiu Co (MC), the Chargut Co (CC), the Uruni Co (UC), the Yoqag Co (YC) and the Chikul Co (CK) (Table I, Fig. 1). Collection was performed in June 2015 and June 2017 using floating gillnets (mesh sizes of 30-40 mm). For each sample, a total length (TL, to the nearest $0.1 \mathrm{~cm}$ ), standard length (SL, to the nearest $0.1 \mathrm{~cm}$ ) and total weight (TW, to the nearest $0.1 \mathrm{~g}$ ) were recorded. The pair of lapillar otoliths 
Table I. Summary of sample data.

\begin{tabular}{lllll}
\hline Lake & Code & N & Standard length range $($ mean \pm SD $) / \mathbf{m m}$ & Standard weight range $(\mathbf{m e a n} \pm$ SD $) / \mathbf{g}$ \\
\hline Bochu tsangpo & BT & 40 & $137-300(189.10 \pm 36.80)$ & $34.2-362.9(103.18 \pm 71.96)$ \\
Chargut tsangpo & CT & 50 & $205-355(296.24 \pm 41.26)$ & $97.4-529.2(284.06 \pm 144.35)$ \\
Tsachu tsangpo & TT & 52 & $260-388(322.08 \pm 29.76)$ & $118.3-788.4(459.08 \pm 129.82)$ \\
Nagtsang Co & NC & 16 & $205-325(260.63 \pm 35.11)$ & $111.6-435.5(224.54 \pm 90.79)$ \\
Kyaring Co & KC & 37 & $302-430(359.92 \pm 50.30)$ & $316.3-899.2(544.78 \pm 183.21)$ \\
Mokiu Co & MC & 19 & $232-399(318.00 \pm 49.86)$ & $167.3-1370.8(514.91 \pm 270.95)$ \\
Chargut Co & CC & 22 & $210-375(285.64 \pm 43.13)$ & $105.5-643.1(274.08 \pm 119.46)$ \\
Siling Co & SC & 32 & $233-355(286.44 \pm 31.67)$ & $126.7-587(296.01 \pm 159.87)$ \\
Uruni Co & UC & 25 & $163-433(247.92 \pm 81.12)$ & $53.1-949.4(241.53 \pm 164.64)$ \\
Yoqat Co & YC & 43 & $257-395(321.28 \pm 30.94)$ & $290.7-727.8(459.56 \pm 108.76)$ \\
Chikul Co & CK & 28 & $247-407(305.00 \pm 32.33)$ & $197.6-664.1(318.93 \pm 114.07)$ \\
\hline
\end{tabular}

Note: N, number of samples; SD, standard deviation.

(hereafter referred to as otolith) were extracted, washed with distilled water to remove any additional membranes or surface residues, air dried and stored in labelled plastic tubes.

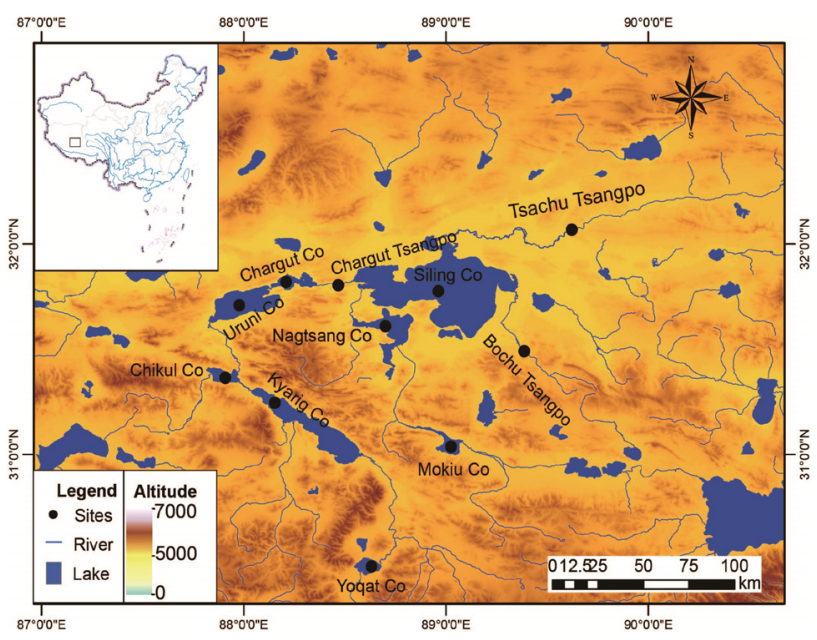

Fig. 1. Study area of northern Tibet and sampling sites (black dot).

\section{Image and shape analysis}

One side of the otolith was selected as the target material; however, one side may not always meet the requirements, as damage occasionally occurred for several otoliths on either side during the extraction procedure. Previous study used the left side of the otolith as a substitute when the right otolith was broken or unavailable (Zischke et al., 2016). Nevertheless, it has been suggested that differences between otoliths from two different sides must be considered in advance, and samples with damaged otoliths have to be discarded if there are significant morphometric differences between the right and left otoliths (Agüera and Brophy, 2011). Several empirical studies have shown consistent shape difference between the left and right otoliths (Mérigot et al., 2007; Vignon and Morat, 2010), whilst no evident differences between two sides of the otoliths were observed in the current observations (Bird et al., 1986; Cardinale et al., 2004; Ding et al., 2019). However, shape variation between two sides of otoliths was still unknown for G. selincuoensis. Thus, we performed examinations firstly to test the differences of shape descriptors between right and left otoliths. In this work, only the samples with at least one intact otolith were used for otolith measurements. Right otoliths were selected for analysis, and left otoliths were substituted only if there was no difference between two sides of otoliths.

All otoliths were weighed to the nearest $0.1 \mathrm{mg}$. High resolution images of the otoliths were captured with a digital camera (Micro Publisher 5.0 RTV) fitted to a stereo microscope (Olympus BX51; Tokyo, Japan) under appropriate magnification and using reflected light. Otoliths were put on a stage of microscope slides in a consistent manner; they were placed along the longest axis with the sulcus side up and rostrum to the right. Photographs were taken on a black background with scale bars under respective magnifications (Longmore et al., 2010).

Image Pro-plus 6.0 software was used to measure otolith size (area, perimeter, length, width) in otolith outlines. Length and width of each otolith was the maximum horizontal axis and maximum vertical axis of the two-dimensional images. These otolith measurements were then used to calculate the following shape indices (SDs): form-factor (FFO), circularity (CIR), rectangularity 
(REC), ellipticity (ELL), roundness (RND), surface density (SDE) and aspect ratio (ARO) based on the equations proposed by Tuset et al. (2003) (Table II).

Table II. Size parameters and shape indices with calculation formulae for otolith of Schizothoracine.

\begin{tabular}{ll}
\hline Size parameter & Shape indices \\
\hline Otolith area $(\mathrm{OA})$ & Form-factor $(\mathrm{FFO})=4 \pi \mathrm{OA} / \mathrm{OP}^{\wedge} 2$ \\
Otolith perimeter $(\mathrm{OP})$ & Circularity $(\mathrm{CIR})=\mathrm{OP}^{\wedge} 2 / \mathrm{OA}$ \\
Otolith length $(\mathrm{OL})$ & Rectangularity $(\mathrm{REC})=\mathrm{OA} /(\mathrm{OL} \times \mathrm{OW})$ \\
Otolith width $(\mathrm{OW})$ & Ellipticity $(\mathrm{ELL})=(\mathrm{OL}-\mathrm{OW}) /(\mathrm{OL}+\mathrm{OW})$ \\
Otolith weight $(\mathrm{OWE})$ & Roundness $(\mathrm{RND})=4 \mathrm{OA} / \pi \mathrm{OL}{ }^{\wedge}$ \\
& Surface density $(\mathrm{SDE})=\mathrm{OWE} / \mathrm{OA}$ \\
& Aspect ratio $(\mathrm{ARO})=\mathrm{OL} / \mathrm{OW}$ \\
\hline
\end{tabular}

Note: units are $\mathrm{mm}^{2}$ for $\mathrm{OA}, \mathrm{mm}$ for $\mathrm{OP}, \mathrm{OL}, \mathrm{OW}$, and $\mathrm{mg}$ for OWE in this paper.

In this study, the SHAPE ver 1.3 program (Iwata and Ukai, 2002) was operated to extract EFDs from the twodimensional otolith images. In this software package, the Chain Coder program was used to describe the contours of the otoliths and stored the information as chain-codes. The Chc2Nef program generated normalized EFDs coefficients (NEFDs) of each otolith with the chain-code produced in the first step. EFDs coefficients were normalized by size and orientation, and the program gave the first three coefficients values as $\mathrm{a} 1=1, \mathrm{~b} 1=0$, and $\mathrm{c} 1=0$.

The technique of elliptic Fourier analysis describes the otolith outline as harmonic. A sufficient number of harmonics have to be determined for a fish species to construct the otoliths in detail (Crampton, 1995). Cumulative percentages of Fourier Power that were calculated in previous studies were used to measure the descriptive ability of each otolith (Trojette et al., 2014; Vieira et al., 2014). Thus, we calculated Fourier power spectrum for $G$. selincuoensis otoliths to define the appropriate number of harmonics needed for each otolith.

\section{Multivariate statistical analysis}

SDs and NEFDs coefficients were tested for normality and homogeneity using the Kolmogorov-Smirnov normality test and Levene's test, respectively. Variables were $\log (x+1)$ transformed if they did not agree with the premises; the transformations that could not be normalized or homogenized were excluded from further analyses.

To test the variation between right and left otoliths, pairwise t-test was performed for each shape variable. The correlations of otolith shape variables with standard length among the shape variables themselves were tested by Pearson correlation analysis, and the variables that expressed significant multicollinearity were excluded. Shape variables that have significant correlations with fish size were corrected using the common within-group slope (Bergenius et al., 2006; Tracey et al., 2006). Analysis of Covariance (ANCOVA) was used to determine the effect of fish length on the magnitude of each shape variable. If the interaction between 'region*fish standard length' was significant, the shape variables were excluded from subsequent analyses as they could not be adjusted with fish standard length. Univariate analyses of variance (ANOVAs) were used to test the differences of shape variables between all groups. The variables that have a significant variability were adopted for discriminant analysis. Finally, permutational multivariate analysis of variance (PERMANOVA) based on Bray-Curtis distances with Monte-Carlo tests (9999 random permutations) was performed to test the significant shape difference among regions.

To evaluate the difference in otolith morphology of all stocks, two methods of statistical Non-metric Multidimensional Scaling (NMDS) and Linear Discrimination Analysis (LDA) were carried out using the descriptors mentioned above. Shape variables of SDs and NEFDs were combined for multivariate statistics. During the NMDS analysis, Euclidean distance was calculated, and the ordination plot of Euclidean distance was produced to examine separation and aggregation for inter- and intrastocks, respectively. Stress factors were used to assess the quality of ordination that was given in the result. LDA was applied to investigate the proportion of each sample that could be correctly classified to the sites where they originally belonged. Discriminant power was assessed using Wilks' $\lambda$, which varies between 0 and 1 , with zero indicating a perfect identification. To visualize the outline differences among stocks, average otolith contours were replotted by using averaged NEFDs within each group. All statistical analyses were carried out with a significance level of 0.05 , and multivariable analyses were completed on SPSS (v.16.0). NMDS and LDA were performed using R statistical software (R Core Team, 2018) with the "vegan" and "MASS" R packages.

\section{RESULTS}

\section{Image and shape analysis}

A total of 364 fish individuals were sampled for morphological study, and summaries of the sample data are provided in Table I. Pairwise t-tests showed no evident shape differences between two sides of the otoliths ( $p>0.05$ ) for the descriptors in Table III. A total of 364 intact otoliths, including 11 substituted individuals on the left side, were measured to obtain otolith size descriptors (Table II). 
To determine the appropriate number of harmonics for $G$. selincuoensis otoliths, the cumulative variances of the harmonics were calculated with 1 to 20 harmonics. Otolith contours defined by 2, 6, 10, 14 and 18 harmonics were plotted to show the outline similarities relative to the original otolith. A total of 18 harmonics resulted in 99.99\% Fourier Powers (Fig. 2). Refer to the previous studies that suggested the sufficient percentage of Fourier Power (Lord et al., 2012; Trojette et al., 2014), we used 20 harmonics to extract NEFDs and four coefficients of each harmonic were produced. Seventy-seven coefficients were used in the subsequent shape analyses since the first three coefficients $(\mathrm{a} 1=1, \mathrm{~b} 1=0, \mathrm{c} 1=0)$ were fixed values.

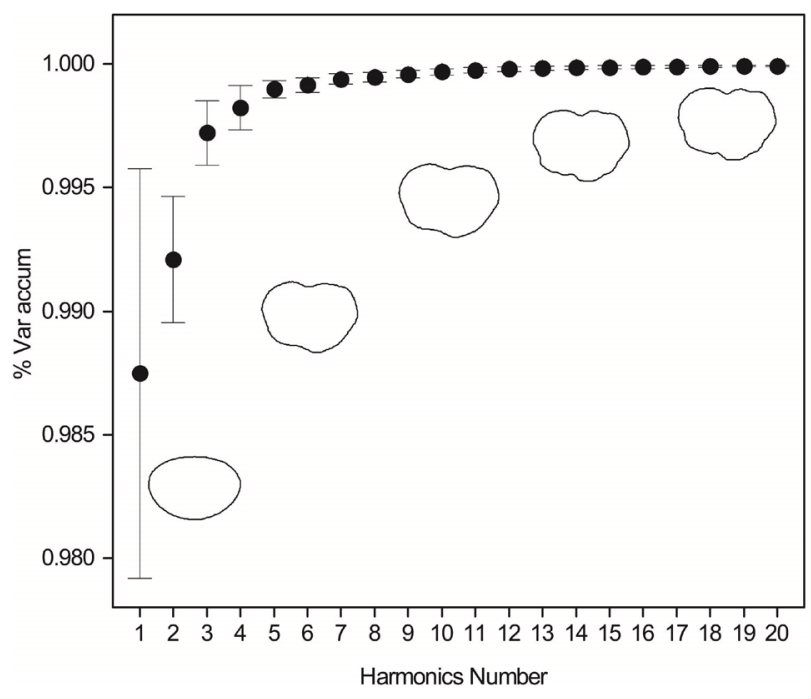

Fig. 2. Periodogram of 20 harmonics for 30 randomly selected otolith of $G$. selincuoensis. Mean (solid dots) and standard deviation (whiskers) represent the accumulated percentage of variance (\% Var accum). Otolith contours shapes defined by $2,6,10,14$ and 18 harmonics were plotted.

\section{Multivariate statistical analysis}

The results showed that SDs of REC and SDE variables did not achieve normality after they were transformed and were thereby removed from further analyses. A total of $80 \%$ of the numbers of NEFDs coefficients were omitted from the analysis as they could not be used (Table III). One-way univariate ANOVAs showed that the rest of the variables for SDs (FFO, CIR, ELL, RND and ARO) and NEFDs $\left(\mathrm{A}_{4}, \mathrm{~A}_{5}, \mathrm{~A}_{17}, \mathrm{~A}_{19}, \mathrm{~B}_{3}\right.$, $\mathrm{C}_{6}, \mathrm{C}_{7}, \mathrm{C}_{17}, \mathrm{D}_{1}, \mathrm{D}_{2}, \mathrm{D}_{3}, \mathrm{D}_{4}$, and $\mathrm{D}_{5}$ ) were significantly different between groups, which meant that these metrics are appropriate for discrimination analysis (Table III). The results of PERMANOVA analysis showed a significant difference between study areas using SDs and
NEFDs $(\mathrm{F}=4.3894, \mathrm{P}<0.001)$.

The results of NMDS showed that otoliths from 11 regions mixed together, while using the SDs and NEFDs for scaling analysis (Fig. 3). All scatters were dispersive and did not gather according to each individual's own stock. Despite the production of low stress factors (stress factor $=0.0013$ ), the analysis of NMDS gave an inconspicuous identification for otoliths among the 11 regions.

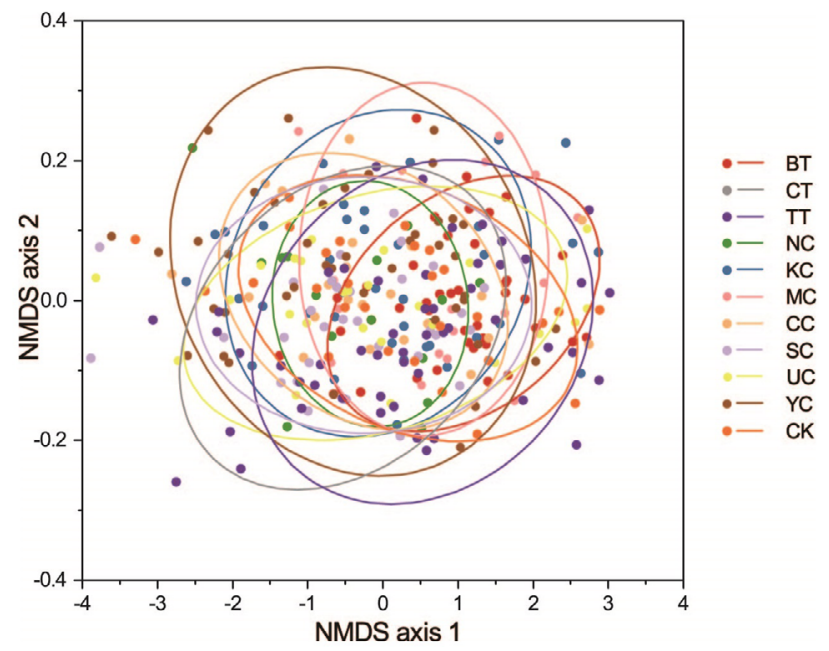

Fig. 3. Non-metric multidimensional scaling (NMDS) ordination plot of otolith from eleven stocks (stress factor $=0.0013$ )

The scatterplot of linear discrimination showed little evidence of separation between stocks. Only group BT exhibited any possibility of being interpreted as an independent stock (Fig. 4). The first two discriminant functions explained $32.58 \%$ and $18.61 \%$ of the total variation, respectively, with levels that were significant $(\mathrm{P}<0.001)$. The classification matrix displayed a correct identification rate ranging from $27.3 \%$ to $70.0 \%$ (Table IV). Three stocks in rivers BT, CT and TT had successful discriminatory rates of $70.0 \%, 44.0 \%$ and $44.2 \%$, respectively, and they were classified more accurately than stocks in the lakes. For example, the CC stocks possessed the highest misclassification rate of $72.7 \%$. The discriminant analysis was significant $(\mathrm{P}<0.05)$ with a low Wilks' $\lambda$ of 0.262 , which implies stronger discriminative power. However, the overall correct classification was not very high $(41.8 \%)$, which verifies that the discriminant analysis using otolith morphology did not improve the effects for $G$. selincuoensis. 
Table III. Coefficients of person's correlation for variables selected for discriminate function analysis with fish standard length. Regression analysis of variables that had significant correlation with fish standard length to get the common within-group slope (b). One-way ANOVAs used to test the difference of variables and rectified variables between the sample regions. Pairwise t-test used to test the difference of variables between right and left otolith.

\begin{tabular}{|c|c|c|c|c|c|c|c|c|c|}
\hline \multirow{2}{*}{$\begin{array}{l}\text { Varia- } \\
\text { bles }\end{array}$} & \multicolumn{2}{|c|}{ Correlation analysis } & \multicolumn{3}{|c|}{ Regression analysis } & \multicolumn{2}{|c|}{ One-way ANOVAs } & \multicolumn{2}{|c|}{ Pairwise t-test } \\
\hline & t & $\mathbf{p}$ & $\mathbf{F}$ & $\mathbf{p}$ & $\mathbf{b}$ & $\mathbf{F}$ & $\mathbf{p}$ & $\mathbf{t}$ & $\mathbf{p}$ \\
\hline FFO & -1.676 & 0.095 & & & & 4.813 & $0.001 * * *$ & -0.820 & 0.416 \\
\hline CIR & 1.832 & 0.068 & & & & 4.788 & $0.001 * * *$ & 0.730 & 0.730 \\
\hline ELL & 7.912 & $0.001 * * *$ & 62.68 & $0.001 * * *$ & $2.01 \times 10^{-4}$ & 6.942 & $0.001 * * *$ & -0.152 & 0.879 \\
\hline RND & 7.972 & $0.001 * * *$ & 63.54 & $0.001 * * *$ & $-3.267 \times 10^{-4}$ & 6.913 & $0.001 * * *$ & 0.207 & 0.836 \\
\hline ARO & 7.854 & $0.001 * * *$ & 61.69 & $0.001 * * *$ & $5.418 \times 10^{-4}$ & 7.043 & $0.001 * * *$ & -0.167 & 0.867 \\
\hline $\mathrm{A}_{4}$ & 1.576 & 0.116 & & & & 2.112 & $0.023^{*}$ & -0.866 & 0.391 \\
\hline $\mathrm{A}_{5}$ & 4.437 & $0.001 * * *$ & 19.69 & $0.001 * * *$ & $3.484 \times 10^{-5}$ & 2.874 & $0.002 * *$ & -0.709 & 0.482 \\
\hline $\mathrm{A}_{17}$ & 1.544 & 0.124 & & & & 2.329 & $0.012 *$ & 0.212 & 0.833 \\
\hline $\mathrm{A}_{19}$ & 2.155 & $0.032 *$ & 4.64 & $0.032 *$ & $3.276 \times 10^{-6}$ & 2.363 & $0.010^{* *}$ & -1.472 & 0.148 \\
\hline $\mathrm{B}_{3}$ & 2.122 & $0.035^{*}$ & 4.50 & $0.035^{*}$ & $3.451 \times 10^{-5}$ & 2.026 & $0.030 *$ & -1.316 & 0.195 \\
\hline $\mathrm{C}_{6}$ & -0.955 & 0.340 & & & & 1.895 & $0.045^{*}$ & -0.320 & 0.750 \\
\hline $\mathrm{C}_{7}$ & -0.464 & 0.643 & & & & 1.938 & $0.039 *$ & 0.616 & 0.541 \\
\hline $\mathrm{C}_{12}$ & -0.189 & 0.851 & & & & 1.977 & $0.035^{*}$ & 1.654 & 0.106 \\
\hline $\mathrm{D}_{1}$ & -6.211 & $0.001 * * *$ & 38.58 & $0.001 * * *$ & $-2.199 \times 10^{-4}$ & 6.961 & $0.001 * * *$ & 0.346 & 0.730 \\
\hline $\mathrm{D}_{2}$ & 1.058 & 0.291 & & & & 2.045 & $0.023^{*}$ & 0.018 & 0.985 \\
\hline $\mathrm{D}_{3}$ & -0.985 & 0.325 & & & & 2.49 & $0.007 * *$ & -1.037 & 0.305 \\
\hline $\mathrm{D}_{4}$ & 1.589 & 0.113 & & & & 2.246 & $0.015^{*}$ & -0.080 & 0.936 \\
\hline $\mathrm{D}_{5}$ & 4.145 & $0.001 * * *$ & 17.18 & $0.001 * * *$ & $4.83 \times 10^{-5}$ & 4.707 & $0.001 * * *$ & -0.103 & 0.918 \\
\hline
\end{tabular}

FFO, form-factor; CIR, circularity; REC, rectangularity; ELL, ellipticity; RND, roundness; SDE, surface density; ARO, aspect ratio; The p-value of each predictor is given as: $* \mathrm{p}<0.05 ; * * \mathrm{p}>0.01 ; * * \mathrm{p}<0.001$.

Table IV. Result from linear discriminant functions of $G$. selincuoensis stocks (abbreviations of site names refer to Table 1). In rows, the numbers out brackets are quantitative proportion of otoliths classified into the sites in columns, and numbers in brackets are counts of otoliths (successful classification given in bold).

\begin{tabular}{|c|c|c|c|c|c|c|c|c|c|c|c|c|}
\hline \multirow[t]{2}{*}{ Site } & \multicolumn{12}{|c|}{ Classification by shape variables } \\
\hline & BT & CT & TT & NC & $\mathrm{KC}$ & MC & $\mathrm{CC}$ & SC & UC & YC & CK & Total \\
\hline $\mathrm{BT}$ & $70.0(28)$ & $0.0(0)$ & $10.0(4)$ & $0.0(0)$ & $0.0(0)$ & $2.5(1)$ & $7.5(3)$ & $2.5(1)$ & $2.5(1)$ & $0.0(0)$ & $5.0(2)$ & $(40)$ \\
\hline $\mathrm{CT}$ & $6.0(3)$ & $44.0(22)$ & $8.0(4)$ & $2.0(1)$ & $16.0(8)$ & $0.0(0)$ & $4.0(2)$ & $2.0(1)$ & $6.0(3)$ & $6.0(3)$ & $6.0(3)$ & $(50)$ \\
\hline TT & $3.8(2)$ & $19.2(10)$ & $44.2(23)$ & $0.0(0)$ & $5.8(3)$ & $1.9(1)$ & $5.8(3)$ & $3.8(2)$ & $3.8(2)$ & $3.8(2)$ & $7.7(4)$ & $(52)$ \\
\hline $\mathrm{NC}$ & $18.8(3)$ & $12.5(2)$ & $0.0(0)$ & $37.5(6)$ & $0.0(0)$ & $0.0(0)$ & $6.3(1)$ & $6.3(1)$ & $6.3(1)$ & $6.3(1)$ & $6.3(1)$ & (16) \\
\hline $\mathrm{KC}$ & $0.0(0)$ & $21.6(8)$ & $13.5(5)$ & $2.7(1)$ & $32.4(12)$ & $8.1(3)$ & $2.7(1)$ & $0.0(0)$ & $2.7(1)$ & $13.5(5)$ & $2.7(1)$ & (37) \\
\hline $\mathrm{MC}$ & $0.0(0)$ & $10.5(2)$ & $31.6(6)$ & $10.5(2)$ & $0.0(0)$ & $36.8(7)$ & $0.0(0)$ & $0.0(0)$ & $5.3(1)$ & $0.0(0)$ & $5.3(1)$ & (19) \\
\hline $\mathrm{CC}$ & $4.5(1)$ & $18.2(4)$ & $9.1(2)$ & $0.0(0)$ & $4.5(1)$ & $0.0(0)$ & $27.3(6)$ & $13.6(3)$ & $0.0(0)$ & $13.6(3)$ & $9.1(2)$ & (22) \\
\hline $\mathrm{SC}$ & $3.1(1)$ & $18.8(6)$ & $18.8(6)$ & $3.1(1)$ & $0.0(0)$ & $0.0(0)$ & $6.3(2)$ & $34.4(11)$ & $9.4(3)$ & $3.1(1)$ & $3.1(1)$ & (32) \\
\hline UC & $16.0(4)$ & $8.0(2)$ & $4.0(1)$ & $8.0(2)$ & $8.0(2)$ & $0.0(0)$ & $0.0(0)$ & $8.0(2)$ & $40.0(10)$ & $4.0(1)$ & $4.0(1)$ & (25) \\
\hline YC & $4.7(2)$ & $18.6(8)$ & $7.0(3)$ & $4.7(2)$ & $9.3(4)$ & $0.0(0)$ & $2.3(1)$ & $7.0(3)$ & $4.7(2)$ & $37.2(16)$ & $4.7(2)$ & (43) \\
\hline $\mathrm{CK}$ & $10.7(3)$ & $10.7(3)$ & $32.1(9)$ & $0.0(0)$ & $7.1(2)$ & $0.0(0)$ & $0.0(0)$ & $0.0(0)$ & $0.0(0)$ & $0.0(0)$ & 39.3(11) & $(28)$ \\
\hline
\end{tabular}




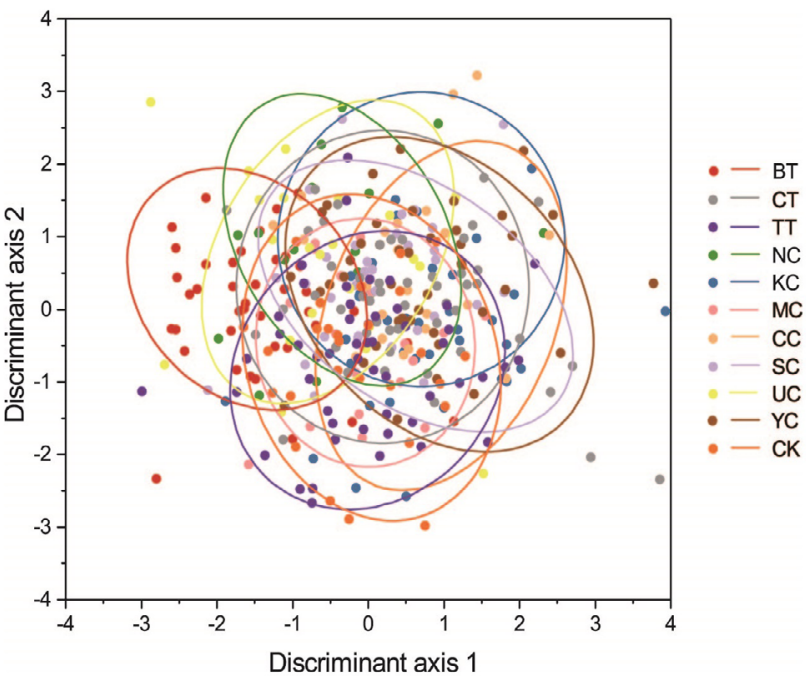

Fig. 4. Linear discriminant analysis scores for the classification of G. selincuoensis in northern Tibet using otolith shape variables including shape indices and Fourier descriptors. The first discriminant axis explained 32.6\% variation and the second axis explained $18.6 \%$ variation (Wilks' $\lambda=0.263$ ).

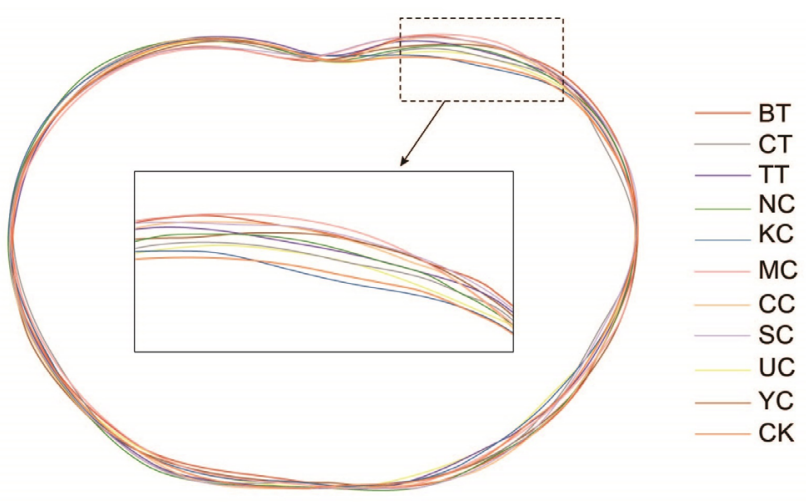

Fig. 5. The average shapes of the lapillus otolith from eleven stocks in northern Tibet. Outlines were rebuilt use average normalized elliptical Fourier coefficients within each stock. One most different area was amplified in black frame.

Average otolith outlines from each stock were repainted using average EFDs and put into a superposition as shown in Figure 5. As the figure shows, the distinctions among 11 stocks were not clearly observed, and the only minor difference appeared in the header position that is magnified in the black box. Otoliths from $\mathrm{KC}$ and $\mathrm{CK}$ had a sunken outline at the upper antirostrum side, and CT stock otoliths had deeper outlines than the other stocks on two sides of the rostrum. The differences in the outlines of each stock were congruent with variations of shape indices.
Figure 6 shows that otolith outlines in BT and MC had a relatively higher FFO but a lower RND and CIR, reflecting that these otolith outlines were more oval in shape. Stocks in TT and CK had lower ARO, which is interpreted from the relatively broad contours.
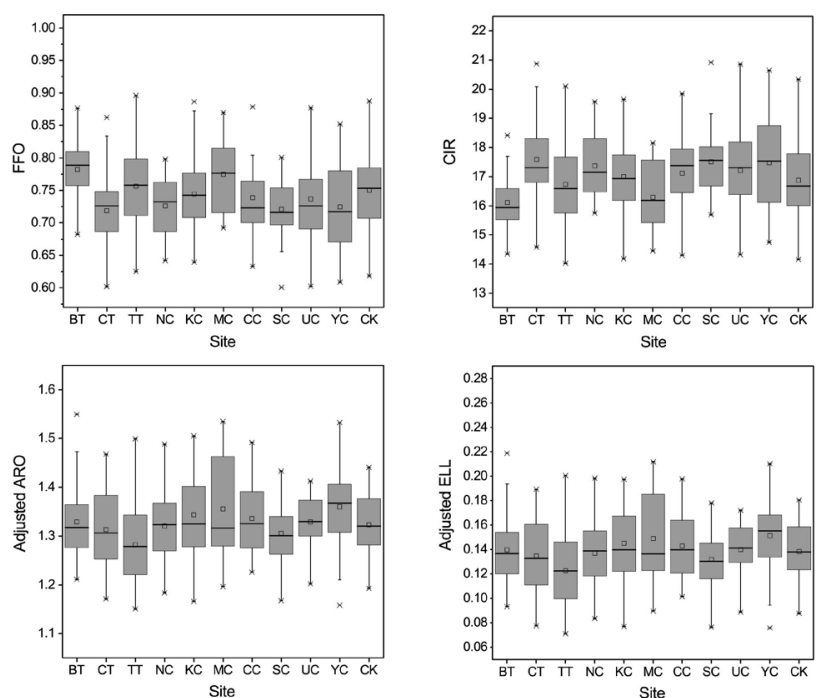

Fig. 6. Boxplots of four shape indices for eleven otolith stocks. Bold transverse line in each box represent the median value and the rectangle means average value.

\section{DISCUSSION}

Otolith shape is proven to serve as a sufficient tool for fish stock discriminations. However, lapillar otoliths are seldom used in morphological analyses since most stock discriminations are developed in marine fish species and sagittal otoliths have the most practicable outlines (Campana and Gagne, 1995). In this study, lapillar otoliths were selected for shape analysis because of their moderate size and convenient collection in species G. selincuoensis (Chen et al., 2009; Li et al., 2009). The results of the Elliptical Fourier analysis demonstrate that lapillar otoliths of $G$. selincuoensis can be described with limited numbers of harmonics (total of 18 harmonics explain $99.99 \%$ of the average Fourier power), suggesting that lapillar otolith shape may be potentially used for morphometric analyses. Differing from previous studies that found significant differences between left and right otoliths (Mérigot et al., 2007; Vignon and Morat, 2010), this study found that lapillar otoliths were the most ideal materials for fish stock discrimination for species G. selincuoensis because they had non-significant shape variation between two sides of the otoliths.

However, the results of the linear discriminant analysis showed that the combination of SDs and NEFDs 
produced a low percent of total successful classification $(41.8 \%)$, with the lowest correct classification for the CC stock $(27.3 \%)$ despite a significant discriminant power produced (lower Wilks' $\lambda$ value). Compared with LDA, NMDS showed a low separation degree of each stock with a small stress factor of 0.0013 , indicating that a perfect fit was given. The main reason might be that dispersion of ordination had concealed the real shape variety, which is in accordance with previous study in identifying Latris lineate stocks (Tracey et al., 2006). A series of investigations also confirmed that otolith shape analysis could be used as natural marker for stock discrimination (Agüera and Brophy, 2011; Bardarson et al., 2017; Soeth et al., 2019; Tracey et al., 2006), and low discriminant power and high misclassification had also been obtained in other works (Cañás et al., 2012; Longmore et al., 2010). Presumably, the discriminant effect was associated with various factors that affected the shape variability and reduced the correct discrimination rates (Cardinale et al., 2004; Vignon and Morat, 2010).

First, previous studies demonstrated that otolith shapes were mainly affected by genetic heterogeneity and environmental disparity (Stransky et al., 2008b). In contrast, Vignon and Morat (2010) elucidated that otolith shape was mainly influenced by environmental variation and that genetic variation affected the otolith shape only locally. Environmental factors, such as temperature hydrogeomorphic and depth, have been confirmed as dominating influential factors on otolith shape (Ding et al., 2019; Stransky et al., 2008a). These factors may influence the fish's metabolism and consequently the growth rate, which changes the otolith deposition rate and results in shape variability, such as otolith length and contours (Gagliano and McCormick, 2004; Lombarte and Lleonart, 1993; Moreira et al., 2019). For G. selincuoensis, previous studies based on D-loop sequence found low genetic divergence across different populations, which indicated low level of population genetic structure (Liang et al., 2017). Besides, in northern Tibet, water temperature, depth and velocity were different between rivers and lakes, and the disparity had been proven to affect the lifestyle of Schzothoracine fishes represented of different otolith growth rate (Tao et al., 2015; Tao et al., 2018a). Therefore, the low successful classifications of lake stocks might be due to the homogeneity of the environmental factors among lakes. However, specific relationships between otolith morphology and environmental factors need further evaluations.

Additionally, the differences of otolith morphology among stocks had strong correlation with various feeding habits (Gagliano and McCormick, 2004). A recent study provided evidence that variations of otolith shapes were determined by dissimilar diets (Zischke et al., 2016). For Schizothoracine fishes, stocks living in rivers and lakes exhibited different growth patterns since climate change affected the food source availability between the two types of water systems differently (Tao et al., 2018b). Analyses on morphometrics of the feeding organ form features found that $G$. selincuoensis displayed distinct differentiations in mouth position, cornified degree of the lower jaw, gill taker number, and other features, between riverine and lacustrine stocks (Liang, 2017). Changes in feeding organs indicated that fish living in lakes for terminal months were fed mainly with aquatic insects, whereas stocks living in rivers with highly cornified lower jaws were fed attached algae ( $\mathrm{Ji}$, 2008). This difference of food might plasticize the otolith shapes and lead to stocks in rivers BT, CT and TT having higher correct classification rates than the other lake stocks. Meanwhile, otoliths, as a calcareous organization, play an important role in ensuring body balance for fish. In this work, relatively high percentages of correct classifications for riverine stocks illustrate that discrepancies in otolith shape may derive from adaptations to water flow features. Current studies showed that otolith shape might change in accordance with a gradient in body shape, which was associated with water flowing characteristics (Bardarson et al., 2017; Haas et al., 2010). Based on our results, otoliths from stocks CT, TT and BT possessed lower FFO, adjusted ARO and adjusted CIR, which suggested otoliths in rivers had a relatively slender shape compared with the otoliths in lakes. To specify the relationship between otolith shape and hydrological characteristics, more studies need to be conducted.

Furthermore, previous studies found that otolith shape analysis was not suitable for deep-water fish species stock discrimination since its slow growth characteristic could reduce otolith shape variation from different regions (DeVries et al., 2002; Longmore et al., 2010; Stransky, 2005). G. selincuoensis living in the Tibetan Plateau have the special characteristic of low growth rate $(>25$ years individuals which can reach up to $43 \mathrm{~cm}$ in length and $1.1 \mathrm{~kg}$ in weight) as an adaptation to the high altitude and low air temperature (Chen et al., 2002). Low growth rate may dampen the divergence of growth trajectories and reduce otolith shape region-specific heterogeneity, thereby weakening the discriminant power as implied by the low total correct classification ratio $(41.8 \%)$ generated in our results (Longmore et al., 2010).

Finally, migrations between spawning and feeding areas also had large effects on otolith shape, which was illustrated by increasing misclassifications in stock discrimination (Zhang et al., 2016). G. selincuoensis in northern Tibet was an anadromous species that usually migrated into rivers or freshwater lakes during its spawning period as the salty 
water in SC was not suitable for eggs and larvae, and adult individuals generally lived in lakes (Ding, 2012). Based on our results, LDA showed that $18.8 \%$ individuals in the SC stock were incorrectly identified as the CT and TT stock, respectively. The reasons might be that samples in SC, CT and TT had highly mixed together, which resulted in low successful discriminant scores. Similar studies suggested that the misclassification rate increased in adjacent sites (Ibáñez et al., 2017), which also supported this explanation Subsequent studies should consider removing similar sites while using fewer groups for comparisons; this strategy may result in better discrimination (Ibáñez et al., 2017).

\section{CONCLUSIONS}

Our study performed using lapillar otolith shape in fish stock discriminant for Schizothoracine fishes in Tibet Plateau. Firstly, low shape variation between right and left otoliths suggested the usefulness of one side otolith in stock discriminant analysis. Secondly, evidence of higher correct identification rates for riverine fish stocks was derived from this study, which supports the idea that differentiation occurs between riverine and lacustrine fish stocks in accordance with previous studies on growth-increment chronologies and feeding organ features (Liang, 2017; Tao et al., 2018b). Moreover, additional investigations about otolith shape variation between other lakes in northern Tibet would benefit from studying environmental factors, which have significant impacts on otolith shape. To confirm the migratory trajectories, further studies are necessary to probe elemental composition in otolith layers. Studies of Schizothoracine stocks in the Siling Co basin must use other methods. Otolith shape analysis can be used as a diagnostic tool for stock discrimination because of its advantages, namely, its low cost and time-efficient, but its feasibility needs to be explored further.

\section{ACKNOWLEDGEMENTS}

This project was supported by the National Natural Science Foundation of China (Grant nos. 31572248 and 31372189) and the National Basic Research Program of China (Grant no. 2014FY210700). We wish to thank Dr. Xiaoyun Sui and Mr. Ren Zhu for their assistance with field sampling and laboratory experiments. The authors declare that the present study was approved by ethical standards (Guidance options on experimental animals) of the Ministry of Science and Technology of the People's Republic of China.

\section{Competing interests}

The authors have declared no competing interests.

\section{REFERENCES}

Agüera, A. and Brophy, D., 2011. Use of saggital otolith shape analysis to discriminate Northeast Atlantic and Western Mediterranean stocks of Atlantic saury, Scomberesox saurus saurus (Walbaum). Fish. Res., 110: 465-471. https://doi.org/10.1016/j. fishres.2011.06.003

Assis, C.A., 2007. The utricular otoliths, lapilli, of teleosts: their morphology and relevance for species identification and systematics studies. Sci. Mar., 69: 259-273. https://doi.org/10.3989/ scimar.2005.69n2259

Avigliano, E., Domanico, A., Sanchez, S. and Volpedo, A.V., 2017. Otolith elemental fingerprint and scale and otolith morphometry in Prochilodus lineatus provide identification of natal nurseries. Fish. Res., 186: 1-10. https://doi.org/10.1016/j. fishres.2016.07.026

Avigliano, E., Rolón, M.E., Rosso, J.J., Mabragaña, E. and Volpedo, A.V., 2018. Using otolith morphometry for the identification of three sympatric and morphologically similar species of Astyanax from the Atlantic Rain Forest (Argentina). Environ. Biol. Fish, 101: 1319-1328. https://doi.org/10.1007/ s10641-018-0779-2

Bacha, M., Jemaa, S., Hamitouche, A., Rabhi, K. and Amara, R., 2014. Population structure of the European anchovy, Engraulis encrasicolus, in the SW Mediterranean Sea, and the Atlantic Ocean: evidence from otolith shape analysis. ICES J. mar. Sci., 71: 2429-2435. https://doi.org/10.1093/icesjms/ fsu097

Bacha, M., Jeyid, A.M., Jaafour, S., Yahyaoui, A., Diop, M. and Amara, R., 2016. Insights on stock structure of round sardinella Sardinella aurita off north-west Africa based on otolith shape analysis. J. Fish Biol., 89: 2153-2166. https://doi.org/10.1111/jfb.13117

Bardarson, H., McAdam, B.J., Thorsteinsson, V., Hjorleifsson, E. and Marteinsdottir, G., 2017. Otolith shape differences between ecotypes of icelandic cod (Gadus morhua) with known migratory behaviour inferred from data storage tags. Can. J. Fish. aquat. Sci., 74: 2122-2130. https://doi.org/10.1139/ cjfas-2016-0307

Begg, G.A., Friedland, K.D. and Pearce, J.B., 1999. Stock identification and its role in stock assessment and fisheries management: an overview. Fish. Res., 43: 1-8. https://doi.org/10.1016/S0165-7836(99)00062- 
Begg, G.A., Overholtz, W.J. and Munroe, N.J., 2001. The use of internal otolith morphometrics for identification of haddock (Melanogrammus aeglefinus) stocks on Georges Bank. Fish. Bull., 99: 1-14.

Bergenius, M.A.J., Begg, G.A. and Mapstone, B.D., 2006. The use of otolith morphology to indicate the stock structure of common coral trout (Plectropomus leopardus) on the Great Barrier Reef, Australia. Fish. Bull., 104: 498-511.

Bian, D., Bian, B., La, B., Wang. C, Y. and Chen, T., 2010. The response of water level of selin co to climate change during 1975-2008. Acta Geogr. Sin., 65: 313-319.

Bird, J.L., Eppler, D.T. and Checkley, D.M., 1986. Comparisons of herring otoliths using fourier series shape analysis. Can. J. Fish. aquat. Sci., 43: 12281234. https://doi.org/10.1139/f86-152

Bostanci, D., Polat, N., Kurucu, G., Yedier, S., Kontas, S. and Darcin, M., 2015. Using otolith shape and morphometry to identify four Alburnus species ( $A$. chalcoides, A. escherichii, A. mossulensis and A. tarichi) in Turkish inland waters. J. appl. Ichthyol., 31: 1013-1022. https://doi.org/10.1111/jai.12860

Burke, N., Brophy, D. and King, P.A., 2008. Otolith shape analysis: its application for discriminating between stocks of Irish Sea and Celtic Sea herring (Clupea harengus) in the Irish Sea. ICES J. mar. Sci., 65: 1670-1675. https://doi.org/10.1093/icesjms/fsn 177

Campana, S.E. and Casselman, J.M., 1993. Stock discrimination using otolith shape analysis. Can. J. Fish. aquat. Sci., 50: 1062-1083. https://doi. org/10.1139/f93-123

Campana, S.E., Chouinard, G.A., Hanson, J.M., Frechet, A. and Brattey, J., 2000. Otolith elemental fingerprints as biological tracers of fish stocks. Fish. Res., 46: 343-357. https://doi.org/10.1016/S01657836(00)00158-2

Campana, S.E. and Gagne, J.A., 1995. Cod stock discrimination using IPCM elemental assays of otoliths. In: Recent developments in fish otolith research, University of South Carolina Press, Columbia SC.

Cañás, L., Stransky, C., Schlickeisen, J., Sampedro, M.P. and Fariña, A.C., 2012. Use of the otolith shape analysis in stock identification of anglerfish (Lophius piscatorius) in the Northeast Atlantic. ICES J. mar. Sci., 69: 250-256. https://doi.org/10.1093/icesjms/ fss006

Cao, W.X., Chen, Y.F., Wu, Y.F. and Zhu, S.Q., 1981. Origin and evolution of Schizothorachine fishes in relation to the upheaval of the Xizang Plateau. In: Studies on the period, amplitude and type of the uplift of the Qinghai-Xizang Plateau (ed. Tibetan expedition team of the Chinese Academy of Science). Science Press, Beijing, pp. 118-130.

Cardinale, M., Doering-Arjes, P., Kastowsky, M. and Mosegaard, H., 2004. Effects of sex, stock, and environment on the shape of known-age Atlantic cod (Gadus morhua) otoliths. Can. J. Fish. aquat. Sci., 61: 158-167. https://doi.org/10.1139/f03-151

Che, X.H., Feng, M., Jiang, H., Xiao, T., Wang, C.Z., Jia, B. and Bai, Y., 2015. Detection and analysis of Qinghai-Tibet Plateau lake area from 2000 to 2013. J. Geo. Inform. Sci., 17: 99-107.

Chen, Y.F. and Cao, W.X., 2000. Schizothoracinae. In: Fauna Sinica, Osteichthyes: Cypriniformes III (ed. P.Q. Yue) Science Press, Beijing. pp. 275-390.

Chen, Y.F., Chen, Y.Y. and He, D.K., 2009. Age and growth of Schizopygopsis younghusbandi younghusbandi in the Yarlung Zangbo River in Tibet, China. Environ. Biol. Fish, 86: 155-162. https://doi.org/10.1007/ s10641-008-9370-6

Chen, Y.F., Chen, Z.M., He, D.K., Cai, B. and Ba, Z., 2001a. Hydrographic features of Sêrling Co, North Tibetan Plateau. J. Lake Sci., 13: 21-28. https://doi. org/10.18307/20010104

Chen, Y.F., He, D.K., Cao, W.X., and Duan, Z.H. 2002. Growth of Selincuo schizothoracini (Gymnocypris selincuoensis) in Selincuo Lake, Tibeten Platean. Acta Zool. Sin., 48: 667-676.

Chen, Y.F., He, D.K. and Chen, Y.Y., $2001 \mathrm{~b}$. Electrophoretic analysis of isozymes and discussion about species differentiation in three species of genus Gymnocypris. Zool. Res., 22: 9-19.

Crampton, J.S., 1995. Elliptic fourier shape analysis of fossil bivalves: Some practical considerations. Lethaia, 28: 179-186. https://doi. org/10.1111/j.1502-3931.1995.tb01611.x

DeVries, D.A., Grimes, C.B. and Prager, M.H., 2002. Using otolith shape analysis to distinguish Eastern gulf of Mexico and Atlantic Ocean stocks of king mackerel. Fish. Res., 57: 51-62. https://doi. org/10.1016/S0165-7836(01)00332-0

Ding, C., Chen, Y., He, D. and Tao, J., 2015. Validation of daily increment formation in otoliths for Gymnocypris selincuoensis in the Tibetan Plateau, China. Ecol. Evol., 5: 3243-3249. https://doi. org/10.1002/ece3.1572

Ding, C.Z., 2012. Early life history of Gymnocypris selincuoensis and its adaptive mechanism to the extreme enviroment of the Qinghai-Xizang Plateau. $\mathrm{Ph} . \mathrm{D}$ thesis, The University of Chinese Academy of 
Sciences, Beijing, China.

Ding, L.Y., Tao, J., Ding, C.Z., Chen, L.Q., Zhang, C., Xiang, Q.Q. and Sun, J., 2019. Hydrogeomorphic factors drive differences in otolith morphology in fish from the Nu-Salween River. Ecol. Freshw. Fish, 28: 132-140. https://doi.org/10.1111/eff.12437

Dou, S., Yu, X. and Cao, L., 2012. Otolith analysis and its application in fish stock discrimination: A case study. Oceanol. limnol. sin., 43: 702-712.

Gagliano, M. and McCormick, M.I., 2004. Feeding history influences otolith shape in tropical fish. Mar. Ecol. Prog. Ser, 278: 291-296. https://doi. org $/ 10.3354 /$ meps 278291

Haas, T.C., Blum, M.J. and Heins, D.C., 2010. Morphological responses of a stream fish to water impoundment. Biol. Lett., 6: 803-806. https://doi. org/10.1098/rsbl.2010.0401

Härkönen, T.J., 1986. Guide to the otoliths of the bony fishes of the Northeast Atlantic. Danbiu ApS. Biological consultants, Hellerup, Denmark. pp. 256.

He, D., Chen, Y., Liu, C., Tao, J., Ding, C. and Chen, Y., 2016. Comparative phylogeography and evolutionary history of schizothoracine fishes in the Changtang Plateau and their implications for the lake level and Pleistocene climate fluctuations. Ecol. Evol., 6: 656-674. https://doi.org/10.1002/ece3.1890

He, D.K. and Chen, Y.F., 2007. Molecular phylogeny and biogeography of highly specialized grade schizothoracine fishes (Teleostei: Cyprinidae) inferred from cytochrome $b$ sequences. Chin. Sci. Bull., 52: 303-312. https://doi.org/10.1007/s11434007-0123-2

Ibáñez, A.L., Hernandez-Fraga, K. and AlvarezHernandez, S., 2017. Discrimination analysis of phenotypic stocks comparing fish otolith and scale shapes. Fish. Res., 185: 6-13. https://doi. org/10.1016/j.fishres.2016.09.025

Ihssen, P.E., Booke, H.E., Casselman, J.M., Mcglade, J.M., Payne, N.R. and Utter, F.M., 1981. Stock identification: materials and methods. Can. J. Fish. aquat. Sci., 38: 1838-1855. https://doi.org/10.1139/ f81-230

Iwata, H. and Ukai, Y., 2002. SHAPE: A computer program package for quantitative evaluation of biological shapes based on Elliptic Fourier descriptors. J. Hered., 93: 384-385. https://doi. org/10.1093/jhered/93.5.384

$\mathrm{Ji}, \mathrm{Q} ., 2008$. The study on the morphology of feeding organs and the feeding habitats of six Schizothoracine fishes. Master's thesis. Huazhong Agricultural University, Wuhan, Hubei, China.

Jia, Y.T. and Chen, Y.F., 2009. Otolith microstructure of Oxygymnocypris stewartii (Cypriniformes, Cyprinidae, Schizothoracinae) in the Lhasa River in Tibet, China. Environ. Biol. Fish, 86: 45-52. https:// doi.org/10.1007/s10641-008-9334-x

Kuhl, F.P. and Giardina, C.R., 1982. Elliptic Fourier features of a closed contour. Comput. Vision. Graph., 18: 236-258. https://doi.org/10.1016/0146664X(82)90034-X

Li, X.Q., Chen, Y.F., He, D.K. and Chen, F., 2009. Otolith characteristics and age determination of an endemic Ptychobarbus dipogon Regan, 1905) (Cyprinidae: Schizothoracinae) in the Yarlung Tsangpo River, Tibet. Environ. Biol. Fish., 86: 53-61. https://doi. org/10.1007/s10641-008-9420-0

Liang, Y., He, D., Jia, Y., Sun, H. and Chen, Y., 2017. Phylogeographic studies of schizothoracine fishes on the central Qinghai-Tibet Plateau reveal the highest known glacial microrefugia. Sci. Rep-UK., 7: 10983. https://doi.org/10.1038/s41598-017-11198-w

Liang, Y.Y., 2017. Speciation and phylogeography of schizothoracine fishes in Siling Co Basin, north Tibetan Plateau. Ph.D thesis, The University of Chinese Academy of Sciences, Beijing, China.

Lombarte, A. and Lleonart, J., 1993. Otolith size changes related with body growth, habitat depth and temperature. Environ. Biol. Fish., 37: 297-306. https://doi.org/10.1007/BF00004637

Longmore, C., Fogarty, K., Neat, F., Brophy, D., Trueman, C., Milton, A. and Mariani, S., 2010. A comparison of otolith microchemistry and otolith shape analysis for the study of spatial variation in a deep-sea teleost, Coryphaenoides rupestris. Environ. Biol. Fish., 89: 591-605. https://doi.org/10.1007/s10641-010-96741

Lord, C., Morat, F., Lecomte-Finiger, R. and Keith, P., 2012. Otolith shape analysis for three Sicyopterus (Teleostei: Gobioidei: Sicydiinae) species from new Caledonia and Vanuatu. Environ. Biol. Fish., 93: 209-222. https://doi.org/10.1007/s10641-0119907-y

Ma, R., Yang, G., Duan, H., Jiang, J., Wang, S., Feng, X., Wang, S., Feng, X., Li, A., Kong, F., Xue, B., Wu, J. and Li, S., 2011. China's lakes at present: Number, area and spatial distribution. Sci. China Earth Sci., 54: 283-289. https://doi.org/10.1007/s11430-0104052-6

Mérigot, B., Letourneur, Y. and Lecomte-Finiger, R., 2007. Characterization of local populations of the common sole solea solea (Pisces, Soleidae) in the NW Mediterranean through otolith morphometrics and shape analysis. Mar. Biol., 151: 997-1008. https://doi.org/10.1007/s00227-006-0549-0 
Moreira, C., Froufe, E., Vaz-Pires, P. and Correia, A.T., 2019. Otolith shape analysis as a tool to infer the population structure of the blue jack mackerel, Trachurus picturatus, in the NE Atlantic. Fish. Res., 209: 40-48. https://doi.org/10.1016/j. fishres.2018.09.010

Neves, A., Sequeira, V., Farias, I., Vieira, A.R., Paiva, R. and Gordo, L.S., 2011. Discriminating bluemouth, Helicolenus dactylopterus (Pisces: Sebastidae), stocks in Portuguese waters by means of otolith shape analysis. J. mar. Biol. Assoc. U.K., 91: 12371242. https://doi.org/10.1017/S002531541000189X

R Core Team, 2018. $R$ : A language and environment for statistical computing. R Foundation for Statistical Computing, Vienna, Austria. https://www.R-project. org/.

Secor, D.H., 2013. The unit stock concept: Bounded fish and fisheries. In: Stock identification methods (eds. S.X. Cadrin, L.A. Kerr and S. Mariani), $2^{\text {th }}$ ed. Academic Press, New York, pp. 7-28. https://doi. org/10.1016/B978-0-12-397003-9.00002-3

Soeth, M., Spach, H.L., Daros, F.A., Adelir-Alves, J., de Almeida, A.C.O. and Correia, A.T., 2019. Stock structure of atlantic spadefish Chaetodipterus faber from Southwest Atlantic Ocean inferred from otolith elemental and shape signatures. Fish. Res., 211: 8190. https://doi.org/10.1016/j.fishres.2018.11.003

Stransky, C., 2005. Geographic variation of golden redfish (Sebastes marinus) and deep-sea redfish $(S$. mentella) in the north atlantic based on otolith shape analysis. ICES J. mar. Sci., 62: 1691-1698. https:// doi.org/10.1016/j.icesjms.2005.05.012

Stransky, C., Baumann, H., Fevolden, S.E., Harbitz, A., Hoie, H., Nedreaas, K.H., Salberg, A. B. and Skarstein, T.H., 2008a. Separation of Norwegian coastal cod and Northeast Arctic cod by outer otolith shape analysis. Fish. Res., 90: 26-35. https://doi. org/10.1016/j.fishres.2007.09.009

Stransky, C., Murta, A.G., Schlickeisen, J. and Zimmermann, C., 2008b. Otolith shape analysis as a tool for stock separation of horse mackerel (Trachurus trachurus) in the Northeast Atlantic and Mediterranean. Fish. Res., 89: 159-166. https://doi. org/10.1016/j.fishres.2007.09.017

Tao, J., Chen, Y., He, D. and Ding, C., 2015. Relationships between climate and growth of Gymnocypris selincuoensis in the Tibetan Plateau. Ecol. Evol., 5: 1693-1701. https://doi.org/10.1002/ece3.1463

Tao, J., He, D., Kennard, M.J., Ding, C., Bunn, S.E., Liu, C., Jia, Y., Che, R. and Chen, Y., 2018a. Strong evidence for changing fish reproductive phenology under climate warming on the Tibetan Plateau.
Global Change Biol., 24: 2093-2104. https://doi. org/10.1111/gcb.14050

Tao, J., Kennard, M.J., Jia, Y. and Chen, Y., 2018 b. Climate-driven synchrony in growth-increment chronologies of fish from the world's largest highelevation river. Sci. Total Environ., 645: 339-346. https://doi.org/10.1016/j.scitotenv.2018.07.108

Torres, G.J., Lombarte, A. and Morales-Nin, B., 2000. Sagittal otolith size and shape variability to identify geographical intraspecific differences in three species of the genus Merluccius. J. mar. Biol. Assoc. U.K., 80: 333-342. https://doi.org/10.1017/ S0025315499001915

Tracey, S.R., Lyle, J.M. and Duhamel, G., 2006. Application of elliptical Fourier analysis of otolith form as a tool for stock identification. Fish. Res., 77: 138-147. https://doi.org/10.1016/j. fishres.2005.10.013

Trojette, M., Fatnassi, M., Ben Alaya, H., Mahouachi, N.E.H., Chalh, A., Quignard, J.-P. and Trabelsi, M., 2014. Applying Sagitta otolith shape in the discrimination of fish populations Scorpaena porcus (Linnaeus, 1758) (Scorpaenidae) in the Tunisian coasts. Cah. Biol. Mar., 55: 499-506.

Tuset, V.M., Lozano, I.J., Gonzalez, J.A., Pertusa, J.F. and Garcia-Diaz, M.M., 2003. Shape indices to identify regional differences in otolith morphology of comber, Serranus cabrilla (L., 1758). J. appl. Ichthyol., 19: 88-93. https://doi.org/10.1046/j.14390426.2003.00344.x

Tuset, V.M., Rosin, P.L. and Lombarte, A., 2006. Sagittal otolith shape used in the identification of fishes of the genus Serranus. Fish. Res., 81: 316-325. https:// doi.org/10.1016/j.fishres.2006.06.020

Vieira, A., Neves, A., Sequeira, V., Paiva, R.B. and Gordo, L.S., 2014. Otolith shape analysis as a tool for stock discrimination of forkbeard (Phycis phycis) in the Northeast Atlantic. Hydrobiology, 728: 103110. https://doi.org/10.1007/s10750-014-1809-5

Vignon, M. and Morat, F., 2010. Environmental and genetic determinant of otolith shape revealed by a non-indigenous tropical fish. Mar. Ecol. Prog. Ser., 411: 231-241. https://doi.org/10.3354/meps08651

$\mathrm{Wu}$, Y.F. and $\mathrm{Wu}$, C.Z., 1992. The fishes of the QinghaiXizang Plateau. Sichuan Publishing House of Science and Technology, Chengdu, China.

Zhang, C., Ye, Z.J., Li, Z.G., Wan, R., Ren, Y.P. and Dou, S.Z., 2016. Population structure of Japanese Spanish mackerel Scomberomorus niphonius in the Bohai Sea, the YellowSea and the East China Sea: Evidence from random forests based on otolith features. Fish. Sci., 82: 251-256. https://doi.org/10.1007/s12562- 
016-0968-x

Zischke, M.T., Litherland, L., Tilyard, B.R., Stratford, N.J., Jones, E.L. and Wang, Y.G., 2016.

Otolith morphology of four mackerel species
(Scomberomorus spp.) in Australia: Species differentiation and prediction for fisheries monitoring and assessment. Fish. Res., 176: 39-47. https://doi. org/10.1016/j.fishres.2015.12.003 